\title{
Determination of Carbamates in Beverages by Liquid-Liquid Extraction with Low Temperature Partitioning and Liquid Chromatography
}

\author{
Simone M. Goulart, ${ }^{a}$ Renata D. Alves, ${ }^{a}$ Washington X. de Paula,${ }^{b}$ José Humberto de Queiroz, ${ }^{c}$ \\ Antônio A. Neves ${ }^{a}$ and Maria Eliana L. R. de Queiroz ${ }^{* a}$ \\ ${ }^{a}$ Departamento de Química, Universidade Federal de Viçosa, \\ Av. P. H. Rolfs, s/n, 36570-000 Viçosa-MG, Brazil \\ ${ }^{b}$ Laboratório de Química Legal, Instituto de Criminalística de Minas Gerais, \\ Rua Juiz de Fora, 400, Barro Preto, 30180-060 Belo Horizonte-MG, Brazil \\ 'Departamento de Bioquímica e Biologia Molecular, Universidade Federal de Viçosa, \\ Av. P. H. Rolfs, s/n, 36570-000 Viçosa-MG, Brazil
}

\begin{abstract}
Carbamatos são os pesticidas mais frequentemente encontrados em alimentos e bebidas de coloração escura em casos de intoxicação acidental ou intencional. Neste trabalho, extração líquido-líquido com partição em baixa temperatura (LLE-LTP) foi otimizada e validada para determinação dos carbamatos aldicarb, carbofuran e carbaril em bebidas de sucos de uva e leite achocolatado. Este método envolve a extração com acetonitrila, partição líquido-líquido em baixa temperatura e análise por cromatografia líquida de alta eficiência com detecção ultravioleta (HPLC-UV). O método é rápido, eficiente e de baixo custo, emprega pequenos volumes de solvente por amostra e não necessita de limpeza dos extratos. O método de extração foi seletivo e apresentou porcentagens de extração acima de $90 \%$. As premissas relacionadas com os testes estatísticos de linearidade foram verificadas e confirmadas. O método de extração e análise foi validado com resultados satisfatórios e pode ser aplicado em análises de rotina e forenses.
\end{abstract}

Carbamates are the pesticides most commonly found in dark colored foods and beverages in cases of accidental or intentional poisoning. In this work, the liquid-liquid extraction with low temperature partitioning (LLE-LTP) was optimized and validated for determination of the carbamates aldicarb, carbofuran and carbaryl in grape juice and chocolate milk beverages. This method involved extraction with acetonitrile, liquid-liquid partition at low temperature and the analysis by high performance liquid chromatography with ultraviolet detection (HPLC-UV). The method is rapid, efficient and of low-cost, employing small volumes of solvent per sample and requiring no cleanup of the extracts. The extraction methodology was selective and presented recovery percentages above $90 \%$. The premises related to the statistical linearity tests were checked and confirmed. The method of extraction and analysis was validated with satisfactory results, and may be applied in forensic and routine analysis

Keywords: carbamates, low temperature partitioning, high performance liquid chromatography, sample preparation, validation

\section{Introduction}

Carbamate insecticides are widely used in gardening and agriculture due to their broad spectrum of activity and relatively short environmental persistence. However, they are potentially toxic to humans, particularly in the context of intentional self-poisoning. ${ }^{1,2}$ Carbamates are found as

*e-mail: meliana@ufv.br commercialized products for agricultural practices and some compounds of this group, with their respective commercial names are: carbaryl $\left(\right.$ Sevin $\left.^{\circledR}\right)$, aldicarb $\left(\right.$ Temik $^{\circledR}$ ) and carbofuran (Furadan ${ }^{\circledR}$ ). From these, aldicarb stands out as the main target on the list of controlled pesticides of the United States Environmental Protection Agency (EPA) due to its elevated toxicity to mammals. ${ }^{3,4}$ The maximum residue level (MRL) of aldicarb ${ }^{5,6}$ and carbofuran ${ }^{6}$ in water is 10 and $7 \mu \mathrm{g} \mathrm{L^{-1 }}$, respectively. In 
milk, the MRLs established for aldicarb, ${ }^{7,8}$ carbofuran $^{8}$ and carbaryl ${ }^{7,8}$ are $0.01,0.01$ and $0.05 \mathrm{mg} \mathrm{kg}^{-1}$, respectively. The MRLs of aldicarb, ${ }^{7,8}$ carbofuran $^{8}$ and carbary $l^{8}$ in grape are $0.20,0.01$ and $0.01 \mathrm{mg} \mathrm{kg}^{-1}$.

Exposures may occur accidentally, with occupational use, or as a result of intentional self-poisoning. Exposure to toxic substances, including pesticides, can cause irreversible damage to humans, including death, and is therefore considered a serious public health problem worldwide. ${ }^{9}$ Several reports have demonstrated that pesticide poisoning has been a long-standing problem through Africa, ${ }^{10}$ Asia, ${ }^{11,12}$ Europe $^{13}$ and Americas. ${ }^{14,15}$ Recently, in Sri Lanka, carbofuran, carbosulfan and fenobucarb were detected in plasma samples from patients with a history of acute carbamate self-poisoning suggesting a mixed exposure. Carbofuran was detected in 158 samples at a concentration ranging from 20.7 to $62,200 \mathrm{ng} \mathrm{mL}^{-1}$. The $\mathrm{LD}_{50}$ (lethal dose, 50\%) for carbofuran ${ }^{16}$ that can cause acute toxicity to mammals through cholinesterase inhibition is $2 \mathrm{mg} \mathrm{g}^{-1}$.

In Brazil, a retrospective study using data gathered by the Toxicological Information Centers and emergency hospital have shown the "chumbinho" (an illegal rodenticide in which the main ingredient is carbamate insecticide aldicarb) was involved in most cases of poisoning. ${ }^{9,15}$

These compounds are commonly found in foods and beverages in cases of accidental or intentional intoxication. ${ }^{17}$ Over the last years, 157 cases involving aldicarb-contaminated commercial products, and liquid or solid foodstuffs (meat, coffee, milk, soup, juice, cookies, and chocolate) were reported in the Rio de Janeiro State. ${ }^{18}$ The commercial formulations of these pesticides present a grayish color and therefore dark colored beverages such as juices and chocolate drinks are frequently employed in food poisoning.

Due to their toxic nature and harmful effect on human organism, a great attention is given to the monitoring of carbamates and their metabolites in the environment. After application to crops, residues of carbamates and its degradation products can be found in the environment and food. Concentrations of $\mathrm{N}$-methylcarbamates were detected in water, ${ }^{19-22}$ soil, ${ }^{23,24}$ selected food ${ }^{18,22,25-27}$ and biologic samples. ${ }^{1,3,28}$ The main metabolites of aldicarb are aldicarb sulfoxide and aldicarb sulfone. ${ }^{29}$ The 3-hydroxycarbofuran and 3-ketocarbofuran are the major metabolites of carbofuran.

The search for more efficient methods to determine pesticide residues should be stimulated from both an environmental as well as an analytical toxicology point of view. ${ }^{17,30-32}$ The identification of these compounds in different matrices as well as their quantification are of interest in the criminal field since the number of human ${ }^{3,17,33-36}$ and animal $^{37-39}$ intoxications has significantly risen.

Several techniques are available for the detection of carbamates in various matrices. Generally, analytical methods utilized for determination of carbamates in these matrices involve laborious steps, consume analysis time and require derivatization procedures,$^{40}$ which are not suitable in emergency cases related to intentional intoxications. ${ }^{17}$ They usually include a liquid-liquid extraction (LLE), ${ }^{18,28}$ solid-phase extraction (SPE), ${ }^{19,22,41-43}$ solid-phase microextraction (SPME), ${ }^{4,45}$ matrix solid-phase dispersion (MSPD), ${ }^{46-48}$ liquid-liquid microextraction, ${ }^{49}$ dispersive liquid-liquid microextraction (DLLME), ${ }^{50,51}$ temperature controlled ionic liquid dispersive liquid phase microextraction, ${ }^{52}$ carbon nanotube reinforced hollow fiber liquid-phase microextraction ${ }^{53}$ or supercritical fluid extraction ${ }^{54}$ followed by gas ${ }^{20,50,55-60}$ or liquid chromatography. ${ }^{1,19,48,49,52,53,61-70}$ The low volatility and the thermolability of these compounds and the high polarities of the transformation products obviously favor the use of column liquid chromatography (LC) as the separation technique.

Due to the low detection levels required by regulatory agencies, efficient sample preparation and trace-level detection are important aspects in an analytical method. The extraction and cleanup steps are sometimes carried out simultaneously using techniques such as solid-phase extraction (SPE) and solvent extraction with low temperature partitioning (SE-LTP).

Recently, SE-LTP (liquid-liquid extraction or solid-liquid extraction with low temperature partitioning) has emerged as an alternative for pesticide extraction in water, ${ }^{64,71}$ milk, ${ }^{72,73}$ honey, ${ }^{74}$ tomato, ${ }^{75}$ fish, ${ }^{76}$ meat and fatty matrices, ${ }^{77}$ virgin olive oil ${ }^{78,79}$ and butter. ${ }^{80}$ One modification for this technique was proposed for quantification of 15 sulfonamides in porcine liver ${ }^{61}$ and four benzodiazepines in human urine. ${ }^{81}$

The method consists of the addition of small portions of acetonitrile to a given sample, which is then placed in a freezer at $-20^{\circ} \mathrm{C}$ for a period of time. The aqueous phase is iced $^{73-75}$ or more recently, just refrigerated ${ }^{64}$ to separate the phases. The analytes preferentially migrate into the organic phase, which is isolated and subsequently analyzed. The advantage of this method is that the sample components remain in the aqueous phase, whereas pesticides are extracted by the organic phase.

Therefore, the solvent extraction with low temperature partitioning $^{74-81}$ (SE-LTP) is promising for the field of analytical chemistry since this technique presents some advantages in relation to other extraction techniques, such as practicability, reduced number of steps and low consumption of organic solvents, as well as being reliable and selective. 
The main objective of this study was to optimize and validate the liquid-liquid extraction with low temperature partitioning (LLE-LTP) method for determination of the carbamates aldicarb, carbofuran and carbaryl in beverages of forensic interest (grape juice and chocolate milk drinks) by high performance liquid chromatography with ultraviolet detection (HPLC-UV).

\section{Experimental}

\section{Equipment}

A Shimadzu LC 20AT liquid chromatograph, equipped with a UV/VIS Shimadzu detector, Shimadzu CTO 10ASVP column oven, Shimadzu SIL 10AF automatic injector and Shimadzu Lab Solutions integration system, was used in this study, along with a Maxi Clean 750 ultra-sonic bath (output of $150 \mathrm{~W}$ and $33 \mathrm{kHz}$ ), a shaker (Tecnal TE - 420, São Paulo, Brazil) operating at 25 and 175 oscillations per min, a vortex (Certomat ${ }^{\circledR}$ MV) and a freezer (Consul, Brazil).

\section{Chromatographic conditions}

For determination of aldicarb, carbofuran and carbaryl, the chromatographic conditions were: Phenomenex Luna $3 \mu \mathrm{m}, 100 \AA \mathrm{C}_{18}$ column $(150 \times 4.6 \mathrm{~mm})$ with a mobile phase of deionized water:acetonitrile, 65:35 (v:v) at $0.8 \mathrm{~mL} \mathrm{~min}{ }^{-1}$, column temperature of $35^{\circ} \mathrm{C}$ and injection volume of $20 \mu \mathrm{L}$. UV detection was performed at $195 \mathrm{~nm}$ for aldicarb and carbofuran and at $213 \mathrm{~nm}$ for carbaryl.

\section{Reagents and solutions}

Standard stock solutions at concentrations of $1000.0 \mathrm{mg} \mathrm{L}^{-1}$ of aldicarb, carbofuran and carbaryl were individually prepared in acetonitrile (J. T. Baker, HPLC grade) and stored in a freezer. From the stock solutions, a working solution was prepared containing the three carbamates at a concentration of $500.0 \mathrm{mg} \mathrm{L}^{-1}$.

The employed solutions were prepared from standards of aldicarb $(99.9 \% \mathrm{~m} / \mathrm{m}$, Sigma Aldrich), carbaryl $(99.8 \% \mathrm{~m} / \mathrm{m}$, Sigma Aldrich) and carbofuran $(99.9 \% \mathrm{~m} / \mathrm{m}$, Sigma Aldrich), using acetonitrile as a solvent (J. T. Baker, HPLC). The solvents acetonitrile (J. T. Baker, HPLC grade), methanol (Mallinckrodt, HPLC grade), hexane (J. T. Baker, HPLC grade), dichloromethane (Mallinckrodt, HPLC grade) and ethyl acetate (Mallinckrodt, HPLC grade) were employed as extractors.

For application of the optimized and validated technique, the commercial products of the carbamates were used: aldicarb $\left(\right.$ Temik $\left.^{\circledR} 150\right)$, carbofuran (Furadan ${ }^{\circledR}$ $100 \mathrm{G})$ and carbaryl (Sevin $\left.{ }^{\circledR} 480 \mathrm{SC}\right)$.

\section{Preparation of fortified samples}

In the optimization and validation process of the method, integral grape juice and sterilized chocolate milk (free of carbamates) of well-known brand names commercialized in Brazil were used. These beverages were fortified with the standard working solution of the three pesticides at a concentration of $5.0 \mathrm{mg} \mathrm{L}^{-1}$. The fortified samples were then left to equilibrate for $3 \mathrm{~h}$.

\section{Optimization of the LLE-LTP method}

The following variables were optimized for the proposed technique: volumetric ratio of sample to extractor mixture, ionic force, composition of the extractor mixture, homogenization procedures, homogenization time and cold partition time. These variables are reported in Table 1.

Table 1. Variables evaluated in the univariate optimization process of the LLE-LTP of carbamates in grape juice and chocolate milk samples

\begin{tabular}{ll}
\hline Variables & Levels \\
\hline Volumetric ratio of sample & $1: 1$ \\
volume $(2 \mathrm{~mL})$ to extractor & $1: 2$ \\
mixture & no ionic force \\
\hline Ionic force & $1.5 \%$ ionic force \\
\hline Extractor mixture $(4.0 \mathrm{~mL})$ & acetonitrile, methanol \\
& hexane:dichloromethane $(85: 15)$ \\
& acetonitrile:ethyl acetate $(81.25: 18.75)$ \\
\hline Homogenization & vortex $(60 \mathrm{~s})$ \\
& ultra-sonic bath $(10$ min $)$ \\
\hline Agitation time / s & shaker $(20$ min) \\
\hline Partition time / h & 30 \\
& 60 \\
& 90 \\
\hline & 1 \\
& 3 \\
& 6 \\
\hline
\end{tabular}

Beverage samples $(2 \mathrm{~mL})$ free of pesticides were transferred to $22 \mathrm{~mL}$ transparent glass flasks and fortified with $40 \mu \mathrm{L}$ of a standard solution containing the pesticides aldicarb, carbofuran and carbaryl at $5.0 \mathrm{mg} \mathrm{L}^{-1}$ and homogenized (vortex, $60 \mathrm{~s}$ ). The fortified samples (in the presence and absence of ionic force) were added to the extractor mixture in different proportions (Table 1). The system was carefully homogenized and the samples refrigerated to $-20{ }^{\circ} \mathrm{C}$ for the previously established time periods (Table 1). After this period, $1 \mathrm{~mL}$ of the organic 
phase was removed. This extract was stored in a glass flask in the freezer until the moment of chromatographic analysis.

The variables of the optimized method were selected in function of the carbamate extraction efficiency in the two beverages of interest. Recovery percentages were calculated using the analytical curve constructed from the extract matrix free of pesticides. The concentration range of the curve varied between 50.0 and $5000.0 \mu \mathrm{g} \mathrm{L}^{-1}$.

Validation of the method

Analytical parameters of the LLE-LTP, including selectivity, limit of detection (LOD), limit of quantification (LOQ), linearity of the method, precision and accuracy were evaluated according to the protocols of the principal regulating agencies. ${ }^{82-85}$ Method validation is an important requirement in the practice of chemical analysis for obtaining reliable data.

In the statistical treatment of analytical curve linearity, an exploratory adjustment of the data from each curve was performed by the ordinary least square method (OLSM) ${ }^{86,87}$ The outlier values were confirmed and treated by the Jackknife standardized residual test, which was successively applied until new dispersed values were not detected or until reaching a maximum exclusion of $22.2 \%$ of the original results. ${ }^{88,89}$ Violation of the premises related to regression analysis were analyzed: normality by the Ryan and Joiner test,${ }^{90}$ homoscedasticity by the modified Levene test ${ }^{91}$ and the Brown and Watson test ${ }^{92}$ and independence of the regression residues by the Durbin and Watson test. ${ }^{93}$ An $F$-test was conducted to verify the fit to the linear model by means of the significance evaluation of the regression and deviation from linearity. ${ }^{94}$

\section{Application of the LLE-LTP}

The validated method was applied to four grape juice samples and four chocolate milk samples free of the pesticides and randomly fortified with the commercial carbamate products in order to simulate a real situation of attempted food poisoning.

A parallel study was performed with four sterilized whole milk samples to which chocolate powder was added to verify differences between purchased chocolate milk and whole milk to which chocolate powder is added.

\section{Results and Discussion}

\section{Chromatographic analysis}

Optimized chromatographic conditions for simultaneous analysis of carbamates allowed good separation of the target substances as shown by the chromatogram presented in Figure 1.

The peaks with retention times $\left(t_{R}\right)$ equal to 7.935 , 13.491 and 16.281 min correspond to aldicarb, carbofuran and carbaryl, respectively.

The ultraviolet detector was selected for simultaneous detection of the carbamates at two wavelengths $(\lambda=195 \mathrm{~nm}$ and $213 \mathrm{~nm}$ ). The wavelength for aldicarb and carbofuran absorption was $195 \mathrm{~nm}$ and for carbaryl $213 \mathrm{~nm}$. Under these conditions, the carbamates were analyzed in $18 \mathrm{~min}$.

\section{Optimization of the LLE-LTP}

To increase the extraction percentage of the pesticides in the organic phase, six variables of the LLE-LTP technique

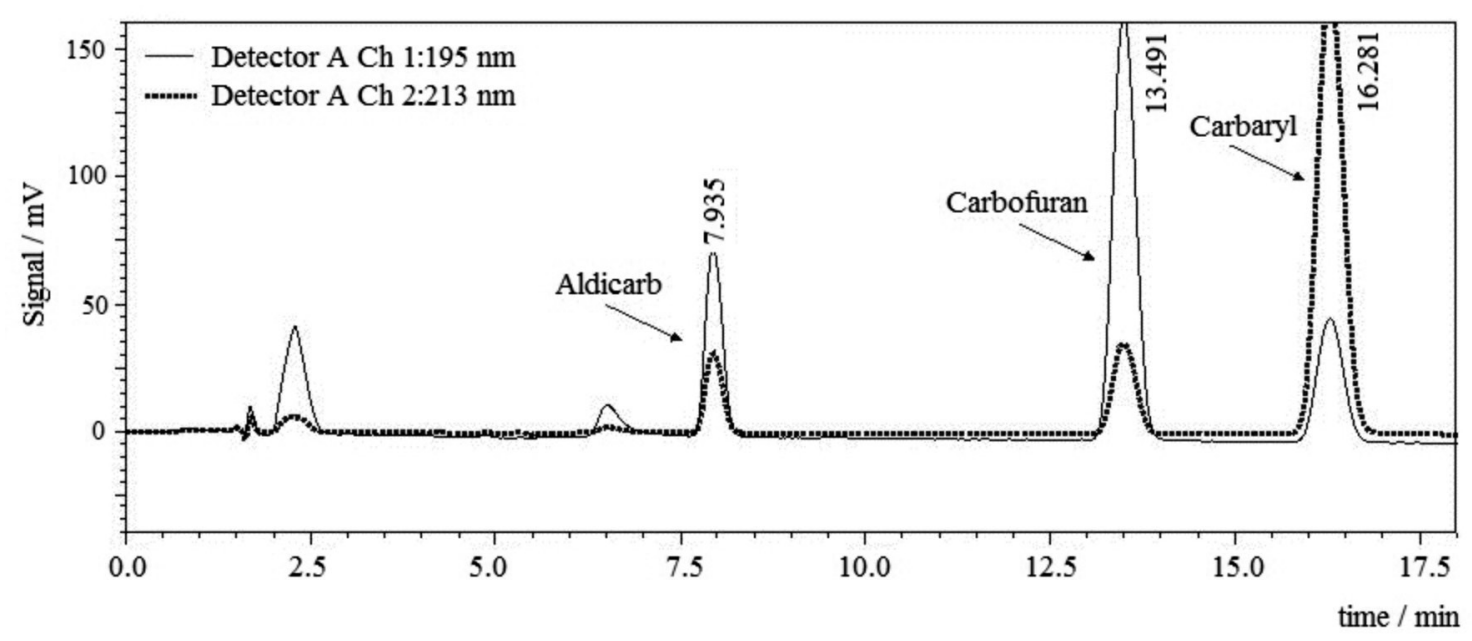

Figure 1. Chromatograms of a standard solution of $5.0 \mathrm{mg} \mathrm{L}^{-1}$ of aldicarb $\left(t_{R}=7.935 \mathrm{~min}\right)$, carbofuran $\left(t_{R}=13.491 \mathrm{~min}\right)$ and carbaryl $\left(t_{R}=16.281 \mathrm{~min}\right)$ in acetonitrile. 
(volumetric ratio of sample to extractor solvent, ionic force, extractor mixture, homogenization, homogenization time and partitioning time) were optimized, as presented in Table 1 in the Experimental section. The extraction percentages for each of the pesticides in the two beverages studied (grape juice and chocolate milk) for each of the optimized conditions are represented in Figures 2 and 3, respectively.

Two proportions of beverage volume to acetonitrile volume were initially utilized $(1: 1$ and $1: 2 \mathrm{v} / \mathrm{v})$. It can be observed in Figures 2a and 3a that the volume increase of acetonitrile from 2 to $4 \mathrm{~mL}$ caused an increase of approximately $21 \%$ in efficiency of pesticide extraction for the three carbamates in the two beverages studied. In the LLE-LTP technique, it was observed in this study, as well as in similar studies, ${ }^{64,71,73,74}$ that a sample to solvent extractor volume of $1: 2(\mathrm{v} / \mathrm{v})$ facilitated the migration of the solutes to the organic phase, independent of the matrix and class of pesticides studied.

(a) Volumetric ratio of sample to solvent

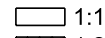
III 1:2

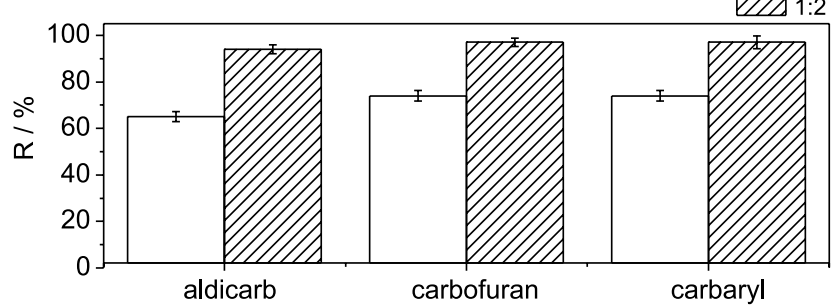

(c) Extractor mixture

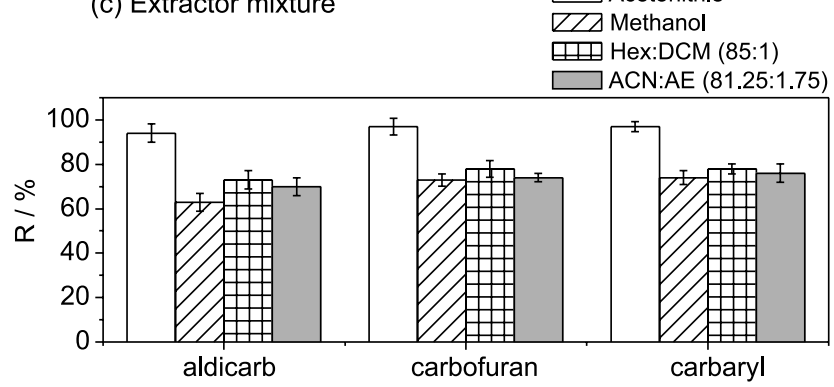

(e) Agitation time-vortex

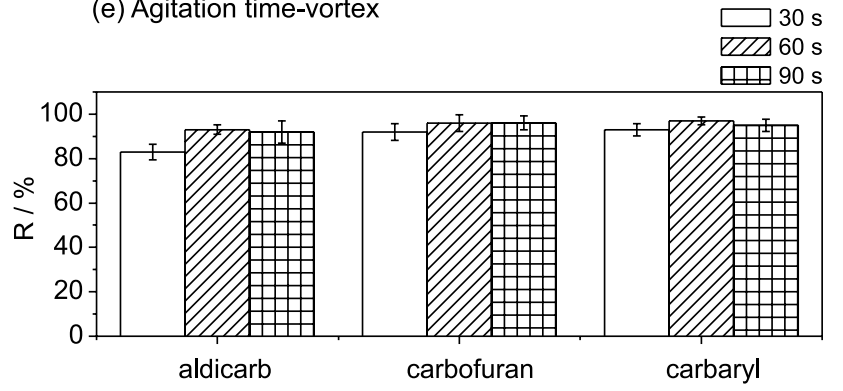

Ionic force

In order to verify the effect of adding salt on the extraction percentage of the carbamates in grape juice and chocolate milk, a study was performed to evaluate the presence of $1.5 \%$ $\mathrm{NaCl}$ in these beverages, as described in Table 1.

When using ionic force in grape juice (Figure 2b), aldicarb recovery percentage was significantly higher. However, the same tendency was not shown for the other pesticides. The increase in ionic force of the aqueous solution by addition of $\mathrm{NaCl}$ caused a positive effect on the extraction due to solvation of the ions by the water molecules, facilitating the migration of the pesticides to the organic phase. However, in some studies, the addition of salt hindered the formation of a single phase, decreasing the percentage of pesticides extracted. ${ }^{71}$

In the chocolate milk beverage (Figure $3 b$ ), the increase in ionic force did not significantly change the extraction percentage of the analytes. This beverage is rich in mineral

(b) lonic force

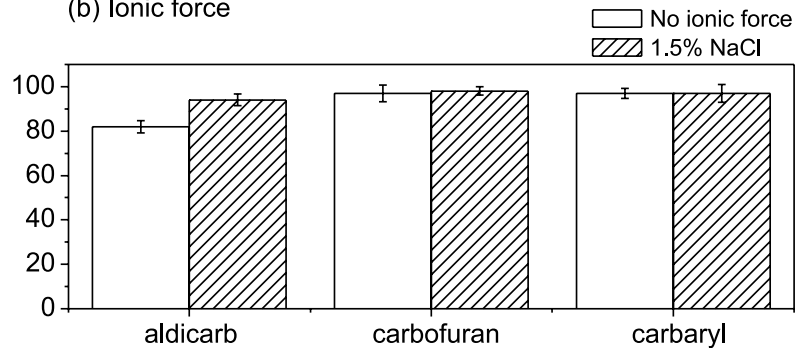

(d) Homogenization

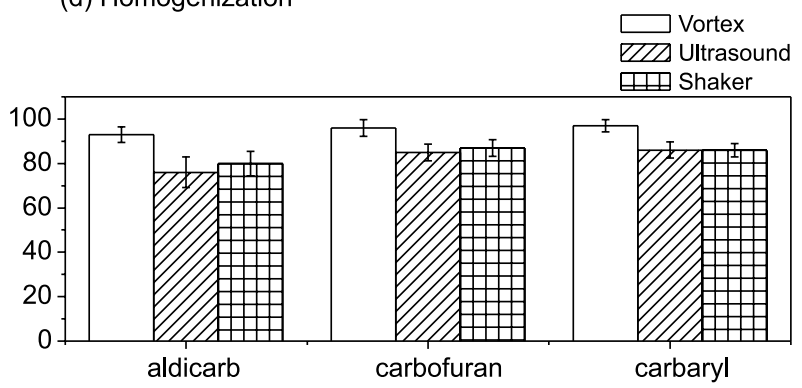

(f) Partitioning time $\square 1 \mathrm{~h}$ EII $3 \mathrm{~h}$ $6 \mathrm{~h}$

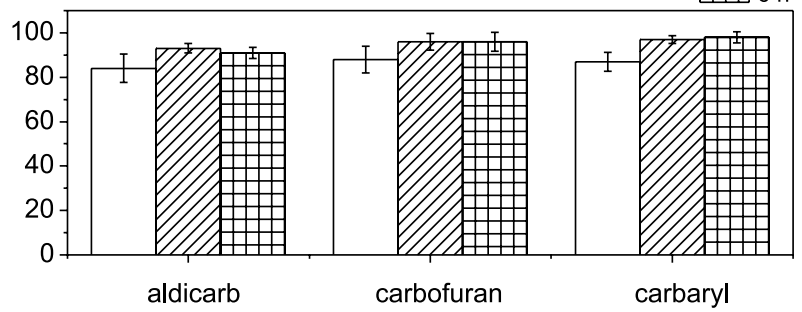

Figure 2. Extraction percentages obtained in optimization of the LLE-LTP technique for pesticides in grape juice: (a) volumetric ratio of sample to solvent, (b) ionic force, (c) extractor mixture, (d) homogenization, (e) agitation time and (f) partitioning time. 
(a) Volumetric ratio of sample to solvent

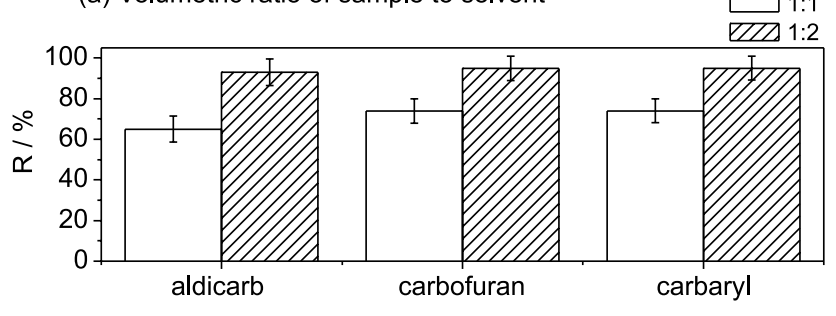

(c) Extractor mixture

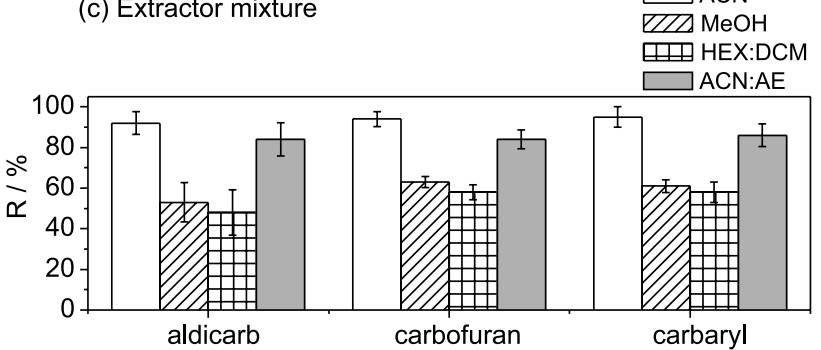

(e) Agitation time-vortex

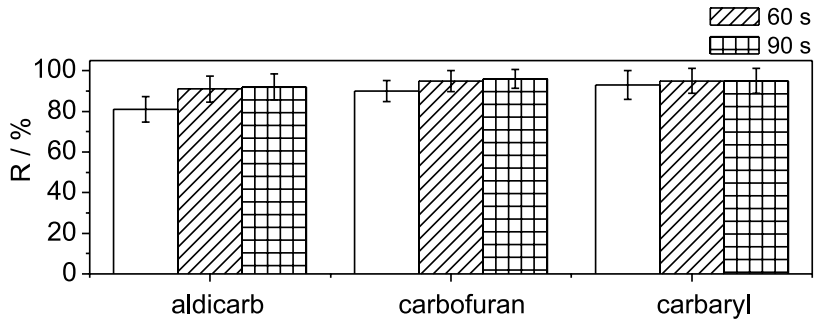

(b) lonic Force

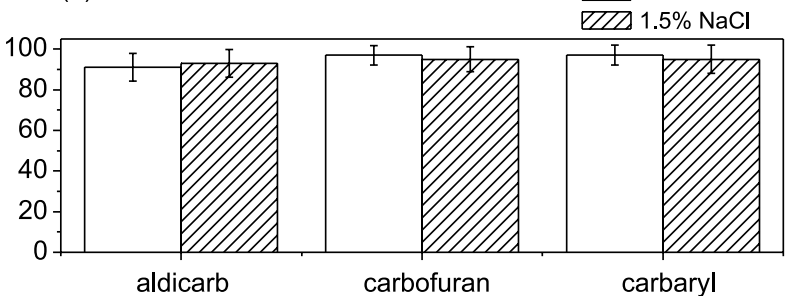

(d) Homogenization

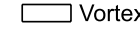
VII Ultrasound Shaker

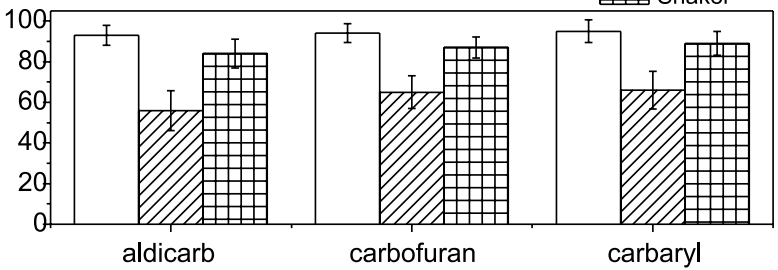

(f) Partitioning time

\section{$\square 1 \mathrm{~h}$ EII $3 \mathrm{~h}$} $6 \mathrm{~h}$

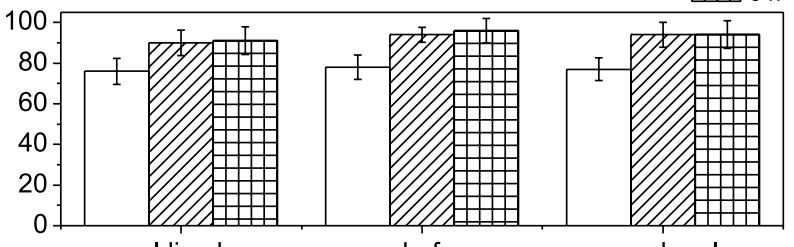

aldicarb carbofuran carbaryl

Figure 3. Extraction percentages obtained in optimization of the LLE-LTP technique for pesticides in chocolate milk: (a) volumetric ratio of sample to solvent, (b) ionic force, (c) extractor mixture, (d) homogenization, (e) agitation time and (f) partitioning time.

salts, so that, the effect of ionic strength by adding salt is negligible.

Based on these results, a step for increasing ionic force by $1.5 \%$ was added in the carbamate extractions from grape juice. In the case of the chocolate milk beverage, this addition of salt is not necessary.

\section{Extractor mixture}

In the two beverages studied, acetonitrile was the solvent which resulted in greatest extraction percentages (above 90\%) for the three carbamates (Figures 2c and 3c). The ethyl acetate solvent presented a retention time close to aldicarb, complicating the quantification of this carbamate. The formation of emulsion occurred in the two beverages when dichloromethane was added to the system, complicating the phase separation. The system continued as a single phase with the addition of methanol, even after the cold partitioning because of the high solubility of this solvent in aqueous medium.

In the chocolate milk beverage, the addition of hexane induced the precipitation of the matrix components, and extraction percentages less than $6 \%$ was obtained. The hexane:dichloromethane mixture at the proportion of 85:15 formed a biphasic system with aqueous medium, both in the grape juice and chocolate milk beverages.

\section{Homogenization process}

Three agitation procedures were evaluated and the results are presented in Figures $2 \mathrm{~d}$ and $3 \mathrm{~d}$. It can be observed that the agitation using the vortex increased the recovery rates for the three pesticides. The $t$-test at a confidence level of 95\% showed that these results were significantly higher than those obtained when employing the shaker or ultrasonic bath. The worst results were obtained when using the ultrasonic bath since this method did not promote effective contact between the two phases, consequently resulting in lower extraction percentages and greater deviations in the analysis.

\section{Agitation time}

Three agitation times in the vortex were studied (30, 60 and $90 \mathrm{~s}$ ). Agitation for $30 \mathrm{~s}$ presented the lowest recovery rates in the two beverages (Figure $2 \mathrm{e}$ and $3 \mathrm{e}$ ), where for aldicarb, this difference was significant in relation to the times of 60 and $90 \mathrm{~s}$ at the confidence level of $95 \%$ by the student $t$-test for the two beverages. 
The agitations for 60 and $90 \mathrm{~s}$ presented no significant differences in the two beverages studied. Therefore, the time of $60 \mathrm{~s}$ was chosen to continue this work.

\section{Low temperature partitioning time}

In this study, it was searched to evaluate the efficiency for the carbamate extractions during partition of the phases by lowering the temperature. The separation of the phases by lowering of the temperature occurs due to reduction of the solubility of the organic solvents in the aqueous medium.

It was observed that for a cooling time less than $3 \mathrm{~h}$, the recovery percentage decreased for the three carbamates (Figures $2 \mathrm{f}$ and $3 \mathrm{f}$ ) indicating that the partition equilibrium is not achieved yet. For cold partition time equal or greater than $3 \mathrm{~h}$, there were no significant differences in recovery percentages at the probability level of $95 \%$ by Tukey test, indicating that the partition equilibrium was achieved. Therefore, the parameter of $3 \mathrm{~h}$ at $-20 \pm 5^{\circ} \mathrm{C}$ was adopted as the partitioning time for this method.

A parallel study in which the aqueous phases were frozen, occurring when the samples remained in the freezer for more than $6 \mathrm{~h}$, was performed to verify the extraction percentage and the presence of interference in the matrix. There was no significant difference in the extraction percentages and the chromatograms were similar to the extracts which remained in the freezer for $3 \mathrm{~h}$. This confirms that the distribution of the analyte between the aqueous and organic phases occurs predominantly before freezing of the sample, which reduces analysis time, increasing analytical frequency. Moreover, the LLE-LTP method, when utilizing $3 \mathrm{~h}$ of partitioning in the freezer for analysis of carbamates in grape juice and chocolate milk beverages, proved to be an efficient technique for the purification of the extracts, for which no preparatory steps are necessary.

\section{Validation of the optimized method}

After optimization of the LLE-LTP method, it was validated for the grape juice and chocolate milk beverages. For this, $2.0 \mathrm{~mL}$ of the beverage was placed in contact with $4.0 \mathrm{~mL}$ of acetonitrile. In the case of grape juice, $1.5 \% \mathrm{NaCl}(\mathrm{w} / \mathrm{v})$ was also added before the contact with the solvent extractor. The system was homogenized in the vortex for $60 \mathrm{~s}$. After agitation, the samples were placed in the freezer for $3 \mathrm{~h}$ for phase separation, and the organic extract $(1.0 \mathrm{~mL})$ was then analyzed by HPLC-UV.

\section{Selectivity}

Selectivity of the method was demonstrated by comparison of the chromatograms obtained at $195 \mathrm{~nm}$ for the fortified grape juice and chocolate milk beverages with the samples free of carbamates (Figures 4 and 5).

The grape juice and chocolate milk beverage samples did not present peaks at the retention times of the carbamates, and the chromatograms of the extracts also presented a satisfactory chromatographic resolution, showing selectivity of the LLE-LTP for more complex matrices.

Limit of detection, limit of quantification and linearity

The limit of detection (LOD) and limit of quantification (LOQ) of the proposed method were determined,

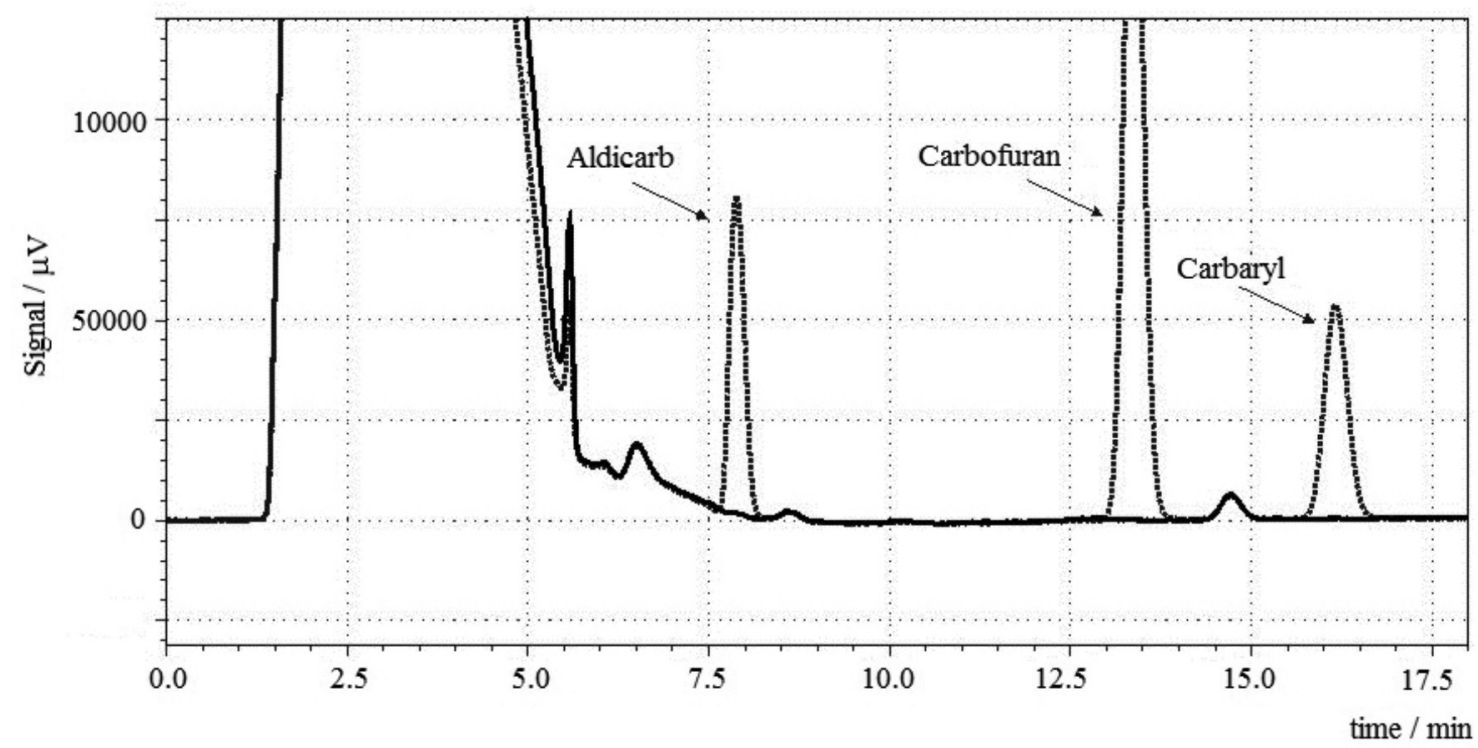

Figure 4. Chromatograms of an extract obtained from grape juice free of active principles ( - ) and of a grape juice extract fortified with $2500.0 \mu \mathrm{g} \mathrm{L}^{-1}$ of the carbamates (-----). 


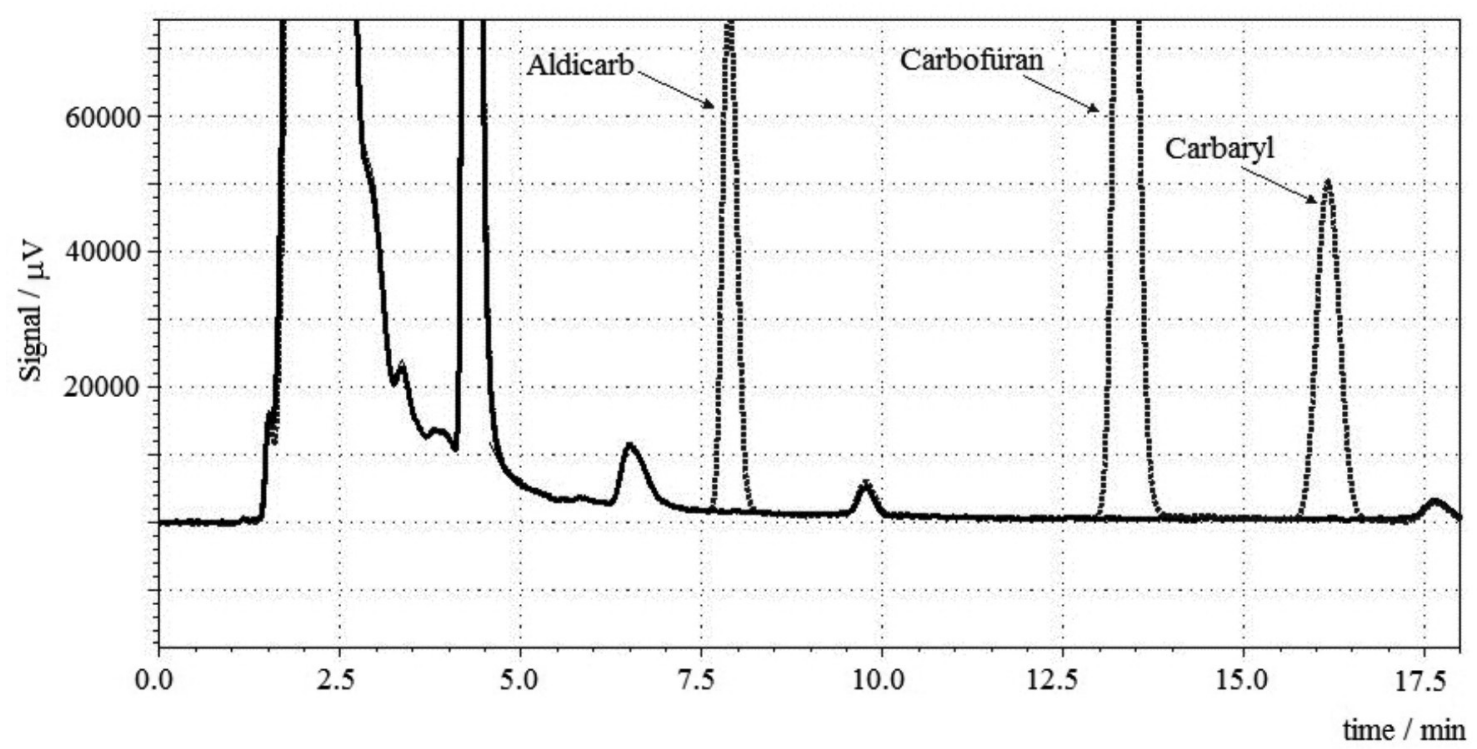

Figure 5. Chromatograms of an extract obtained from the chocolate milk beverage free of active principles ( - ) and of a chocolate milk beverage extract fortified with $2500.0 \mu \mathrm{g} \mathrm{L}{ }^{-1}$ of the carbamates (------).

respectively, as values equal to 3 and 10 times the signal of the baseline (noise) obtained for the beverage (grape juice and chocolate milk beverages) samples free of pesticides (control). The samples fortified with carbamates between 1 and $100 \mu \mathrm{g} \mathrm{L}^{-1}$ were submitted to the LLE-LTP method and analyzed by HPLC-UV. The limits of detection for aldicarb, carbofuran and carbaryl were respectively 15.0, 15.0 and $8.0 \mu \mathrm{g} \mathrm{L}^{-1}$, and the limits of quantification were 50.0, 50.0 and $25.0 \mu \mathrm{g} \mathrm{L}{ }^{-1}$, respectively. These results were similar for the two beverages.

The linearity of the method was evaluated by analyzing the extracts obtained from LLE-LTP of the grape juice and chocolate milk beverage samples fortified with pesticides to obtain the following final concentrations in the extract: $50.0,100.0,500.0,750.0,1000.0,2000.0,3000.0$ and $5000.0 \mu \mathrm{g} \mathrm{L}-1$, with three repetitions for each concentration. The coefficients of determination $\left(\mathrm{R}^{2}\right)$ for the analytical curves of the three pesticides in the two beverages were above 0.99 (Table 2).

The linearity was confirmed for all curves prepared in this work. All identified outlier values were confirmed by the Jacknife standardized residual test, in which no tendencies were observed in the exploratory graphs of regressions of the residuals after treatment of the data. The premise that regression residues should follow normal distribution was confirmed by the Ryan-Joiner test..$^{90}$ The coefficients of determination obtained were greater than 0.99 . These results indicated that the deviation from normality was not significant $(p>0.10)$, permitting the use of the $t$ and $F$ hypothesis tests. The variability of the regression residues along the concentration levels studied was consistent, demonstrating heteroscedasticity. The results of the Levene test were not significant $(p>0.05)$ in all curves examined. The independence of the regression residues was evidenced by the Durbin-Watson test ${ }^{93}$ since the distribution of the points did not show positive or negative tendencies. Therefore, the use of the OLSM was adequate for estimation of the regression parameters. Studies employing statistical tests for validation of the analysis methods in foods have been utilized to give credibility to the results. ${ }^{95}$

\section{Accuracy and precision of the method}

To determine accuracy of the method, beverage samples in triplicate (free of pesticides) were fortified with 100.0,

Table 2. Linearity of the method for grape juice and chocolate milk beverage

\begin{tabular}{|c|c|c|c|c|}
\hline \multirow{3}{*}{ Pesticide } & \multicolumn{4}{|c|}{ Calibration data } \\
\hline & \multicolumn{2}{|c|}{ Grape juice } & \multicolumn{2}{|c|}{ Chocolate milk } \\
\hline & Equation & $\mathrm{R}^{2}$ & Equation & $\mathrm{R}^{2}$ \\
\hline Aldicarb & $y=222.33 x+1862.4$ & 0.9982 & $y=235.14 x-3093.1$ & 0.9997 \\
\hline Carbofuran & $y=717.92 x-37237$ & 0.9958 & $y=735.55 x-19310$ & 0.9999 \\
\hline Carbaryl & $y=801.12 x+8207.8$ & 0.9994 & $y=837.98 x+1754.1$ & 0.9999 \\
\hline
\end{tabular}


200.0 and $1000.0 \mu \mathrm{g} \mathrm{L} \mathrm{L}^{-1}$ of the pesticides. The recovery rates obtained by the proposed method varied from 93 to $97 \%$, with coefficients of variation less than $5 \%$. The precision of the method was determined in terms of the coefficient of variation $(\mathrm{CV})$ for nine identical extraction samples from beverages fortified with $500.0 \mu \mathrm{g} \mathrm{L}^{-1}$ and analysis by HPLC-UV. The results obtained for the grape juice and the chocolate milk beverages are presented in Tables 3 and 4, respectively.

The results presented in Tables 3 and 4 are not significantly different at the probability level of $95 \%$ by the student $t$-test, showing that the recovery percentage is independent of the analyte concentration level in the samples.

\section{Application of the method}

The validated method was applied to the measurement of four samples (free of pesticides) of grape juice and

Table 3. Recovery percentages of the three pesticides, after extraction of the grape juice sample fortified with four different concentrations

\begin{tabular}{lcccccc}
\hline $\begin{array}{l}\text { Concentration } \\
\text { grape juice / } \\
\left(\mu \mathrm{g} \mathrm{L}^{-1}\right)\end{array}$ & \multicolumn{5}{c}{ Average recovery and CV / \% } \\
\cline { 2 - 7 } & Aldicarb & \multicolumn{2}{c}{ Carbofuran } & \multicolumn{2}{c}{ Carbaryl } \\
\hline $100.0^{\mathrm{a}}$ & 94.3 & 2.3 & 96.6 & 2.2 & 96.2 & 1.2 \\
$200.0^{\mathrm{a}}$ & 91.4 & 2.5 & 96.4 & 1.5 & 97.1 & 2.5 \\
$500.0^{\mathrm{b}}$ & 93.4 & 2.0 & 97.0 & 2.9 & 96.8 & 1.5 \\
$1000.0^{\mathrm{a}}$ & 94.2 & 2.2 & 96.9 & 3.2 & 96.9 & 1.5 \\
\hline
\end{tabular}

aResults represent an average of three repetitions; bresults represent an average of nine repetitions. the chocolate milk beverage, fortified at random with the commercial carbamate products. This procedure was performed with the objective of simulating a real food poisoning attempt and verifying if the components of the commercial products interfered with the selectivity of the analysis. A study was completed with four samples of sterilized whole milk to which chocolate powder was added to verify if the results of this matrix are different from those of the commercial chocolate milk beverage.

In all beverage samples extracted by the LLE-LTP method, there was no interference of the commercial product components, as can be observed by the chromatograms in Figures 6 and 7 (grape juice and chocolate milk beverages, respectively). There was also no difference between the results obtained for extracts of the commercial chocolate milk beverage and the whole milk to which chocolate powder was added, confirming robustness of the proposed method to matrix.

Table 4. Recovery percentages of the three pesticides, after extraction of the chocolate milk beverage sample fortified with four different concentrations

\begin{tabular}{lcccccc}
\hline $\begin{array}{l}\text { Concentration } \\
\text { chocolate milk / } \\
\left.(\mu \mathrm{g} \mathrm{L})^{-1}\right)\end{array}$ & \multicolumn{5}{c}{ Average recovery and CV / \% } \\
\cline { 2 - 7 } & Aldicarb & \multicolumn{2}{c}{ Carbofuran } & Carbaryl \\
\hline $100.0^{\mathrm{a}}$ & 93.6 & 4.1 & 95.6 & 4.2 & 96.6 & 4.2 \\
$200.0^{\mathrm{a}}$ & 93.4 & 4.5 & 95.9 & 4.5 & 96.4 & 3.5 \\
$500.0^{\mathrm{b}}$ & 92.8 & 4.9 & 96.8 & 4.0 & 97.6 & 3.8 \\
$1000.0^{\mathrm{a}}$ & 93.7 & 4.2 & 95.9 & 3.7 & 95.9 & 3.6 \\
\hline
\end{tabular}

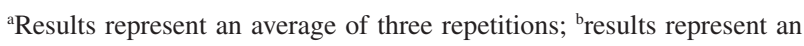
average of nine repetitions.

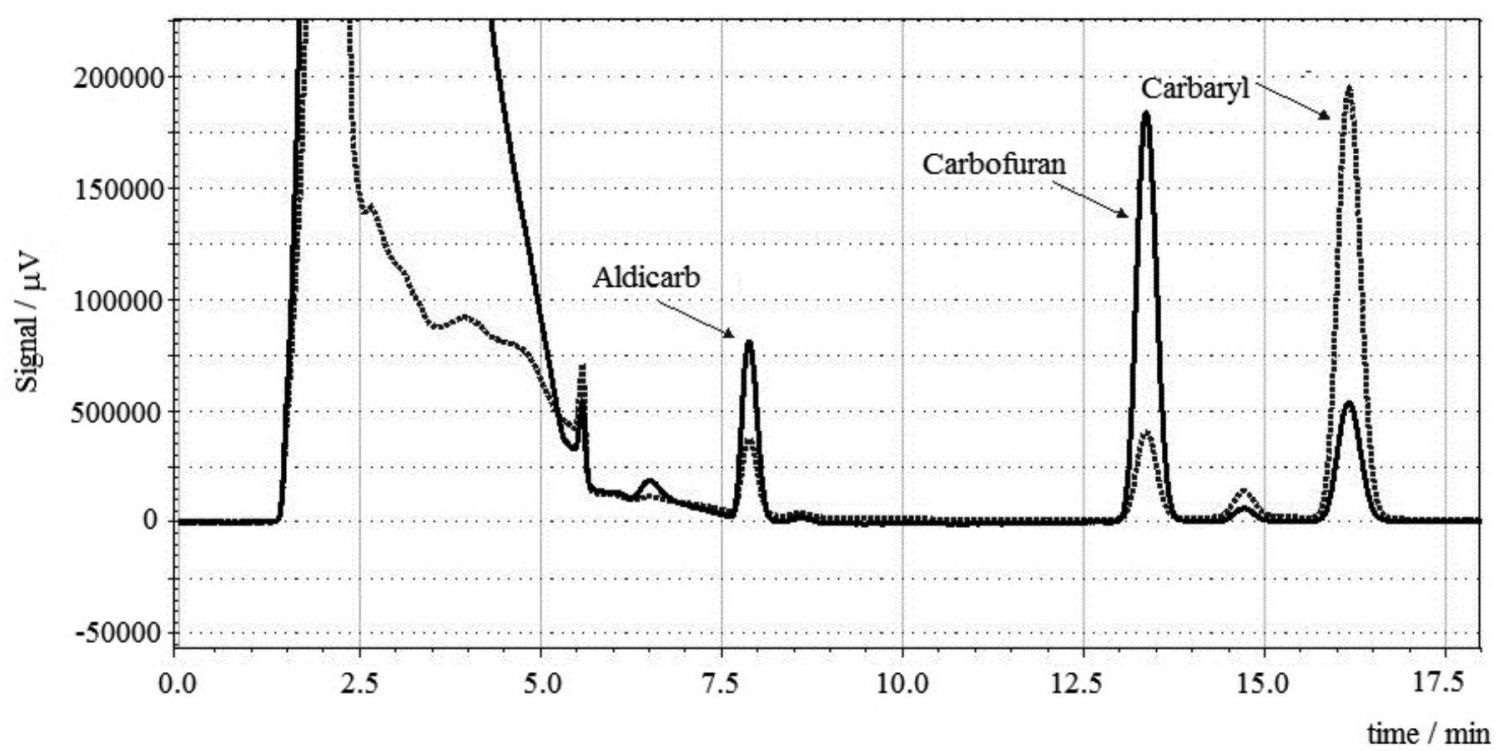

Figure 6. Chromatograms of one extract obtained from grape juice samples to which the commercial carbamates were added and analyzed at 195 (-) and $213 \mathrm{~nm}(------)$. 


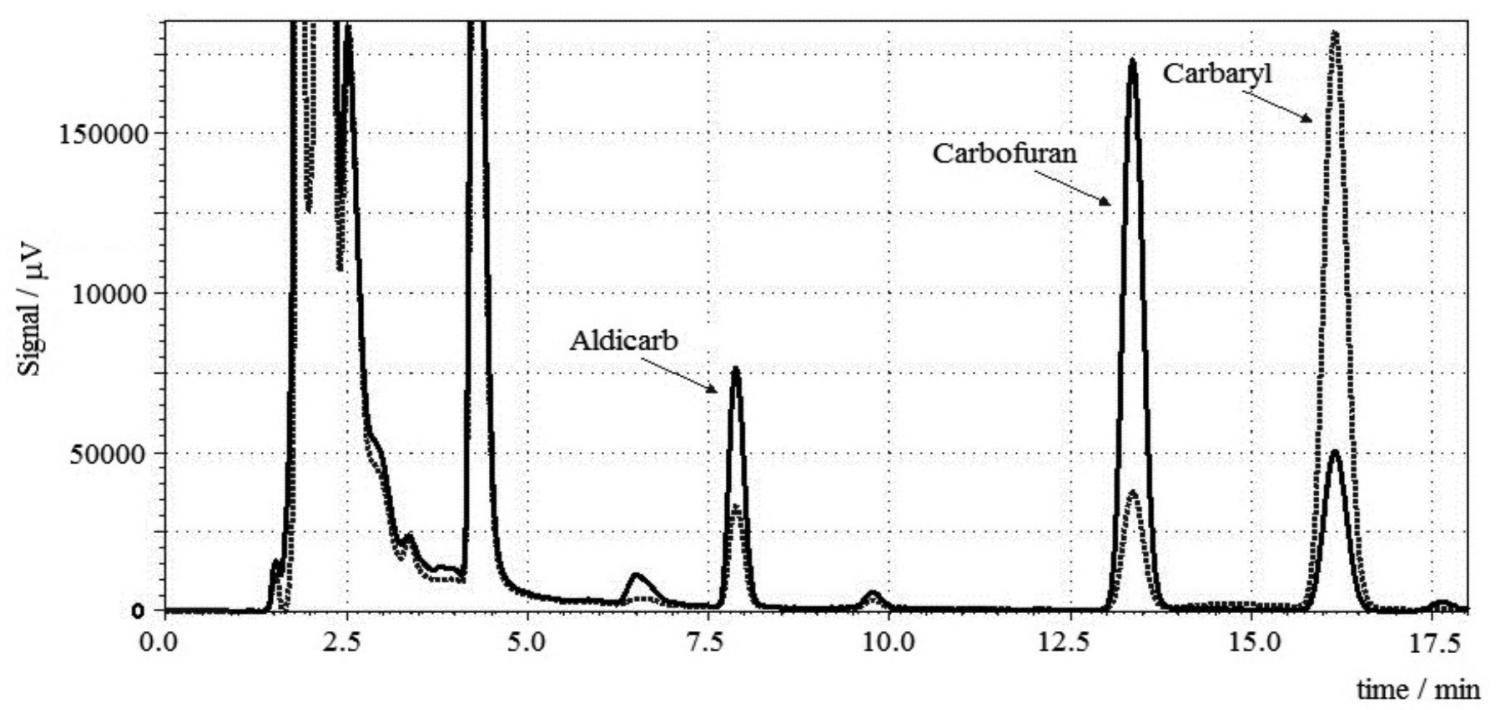

Figure 7. Chromatograms of one extract obtained from the chocolate milk beverage samples to which the commercial carbamates were added and analyzed at $195(-)$ and $213 \mathrm{~nm}(-----)$.

\section{Conclusions}

The optimization of the LLE-LTP method for the carbamate extractions in grape juice and the chocolate milk beverages by HPLC-UV resulted in a quick, effective, selective and low-cost method since the consumption of the utilized organic solvent was minimal $(4.0 \mathrm{~mL})$. The proposed method also presented elevated recovery percentages for the three carbamates (greater than 90\%) in the two studied matrices. The method of extraction and analysis was verified with satisfactory results, and may be recommended for application in forensic and routine analysis.

\section{Acknowledgments}

The authors acknowledge financial support from the Fundação de Amparo à Pesquisa do Estado de Minas Gerais (FAPEMIG) and the Conselho Nacional de Desenvolvimento Científico e Tecnológico (CNPq).

\section{References}

1. Mostafa, A.; Medley, G.; Roberts, D. M.; Mohamed, M. S.; Elshanawani, A. A.; Roberts, M. S.; Liu, X.; J. Chromatogr., B: Anal. Technol. Biomed. Life Sci. 2011, 879, 2234.

2. Maran, E.; Fernández-Franzón, M.; Font, G.; Ruiz, M. J.; Food Chem. Toxicol. 2010, 48, 1592.

3. Proença, P.; Teixeira, H.; Mendonça, M. C.; Castanheira, F.; Marques, E. P.; Corte-Real, F.; Vieira, D. N.; Forensic Sci. Int. 2004, 146S, S79.

4. Environmental Protection Agency (EPA); National Survey of Pesticides in Drinking Water, Phase II Report, EPA 570/9-91-021, United States, 1992.
5. Ministério da Saúde (MS); Procedimentos de Controle e de Vigilância da Qualidade da Água Para Consumo Humano e seu Padrão de Potabilidade, Portaria No. 2914,12 December 2011, Brazil, 2011, available at http://www.comitepcj.sp.gov.br/ download/Portaria_MS_2914-11.pdf accessed in March 2012.

6. World Health Organization (WHO); Guidelines for Drinking Water Quality, Geneva, 2008, available at http://www.who.int/ water_sanitation_health/dwq/fulltext.pdf accessed in March 2012.

7. Codex Alimentarium Commission: Food and Agricultural Organization of the United Nations (FAO) / World Health Organization (WHO); Pesticide Residues in Food, Maximum Residue Limits (MRL's), 2011, available at http://www.codexalimentarius.net/pestres/data/pesticides/ search.html accessed in March 2011.

8. Database: Pesticide Residues MRLs, European Union, 2012, available at http://ec.europa.eu/sanco_pesticides/ public/index.cfm?event=substance.selection accessed in March 2011.

9. Rebelo, F. M.; Caldas, E. D.; Heliodoro, V. O.; Rebelo, R. M.; Ciênc. Saude Coletiva 2011, 16, 3493.

10. Ohayo-Mitoko, G. J. A.; Kromhout, H.; Simwa, J. M.; Boleij, J. S. M.; Heederik, D.; Occup. Environ. Med. 2000, 57, 195.

11. Weissmann-Brenner A.; David, A.; Vidan, A.; Hourvitz, A.; Imaj 2002, 4, 573.

12. Van der Hoek, W.; Konradsen, F.; Athukorala, K.; Wanigadewa, T.; Soc. Sci. Med. 1998, 46, 495.

13. Davanzo, F.; Settimi L.; Faraoni, L.; Maiozzi, P.; Travaglia, A.; Marcello, I.; Epidemiol. Prev. 2004, 28, 330.

14. Ferreira, A.; Maroco, E.; Yonamine, M.; De Oliveira, M. L. F.; Rev. Bras. Cienc. Farm. 2008, 44, 407.

15. Werneck, G. L.; Hasselmann, M. H.; Rev. Assoc. Med. Bras. 2009, 55, 502 . 
16. Environmental Protection Agency (EPA); Interim Reregistration Eligibility Decision: Carbofuran, List [A], Case No. 0101, EPA-738-R-06-031, United States, 2006, p. 38.

17. Lacassie, E.; Marquet, P.; Gaulier, J. M.; Dreyfuss, M. F.; Lachatre, G.; Forensic Sci. Int. 2001, 121, 116.

18. Sabino, B. D.; Torraca, T. G.; Moura, C. M.; Rozenbaum, H. F.; Faria, M. V. C.; J. Forensic Sci. 2010, 55, 808.

19. Carbo, L.; Souza, V.; Dores, E. F. G. C.; Ribeiro, M. L.; J. Braz. Chem. Soc. 2008, 19, 1111.

20. Tariq, M. I.; Afzal, S.; Hussain, I.; Environ. Int. 2004, 30, 471.

21. World Health Organization (WHO); Aldicarb in Drinkingwater; WHO/SDE/WSH/03.04/72; Geneva, 2003, p. 14.

22. Lasera, M. P. G.; Bernal-González, M.; Water Res. 2001, 35, 1933.

23. Castro, N. R. A.; Rigitano, R. L. O.; de Lima, J. M.; Bastos, C. J.; Pesq. Agr. Brasil. 2005, 40, 803.

24. Pessoa, M. C. P. Y.; Chaim, A.; Gomes, M. A. F.; Silva, A. S.; Soares, J. M.; Rev. Bras. Eng. Agr. Amb. 2003, 7, 297.

25. Borkovcová, I.; Janoušková, E.; Řehůřková, I.; Ruprich, J.; Cent. Eur. J. Public Health 2004, 12, 220.

26. Agência Nacional de Vigilância Sanitária (ANVISA); Nota Técnica para Divulgação dos Resultados do PARA de 2008, Brasília, 2009 available at http://www.anvisa.gov.br/ toxicologia/residuos/index.htm accessed in July 2010.

27. Akiyama, Y.; Yoshioka, N.; Tsuji, M.; J. AOAC Int. 2002, 85, 692.

28. Tennakoon, S.; Perera, B.; Haturusinghe, L.; Leg. Med. 2009, $11, \mathrm{~S} 500$.

29. Nunes, G. S.; Alonso, R. M.; Ribeiro, M. L.; Barceló, D.; J. Chromatogr., A 2000, 888, 113.

30. Basheer, C.; Alnedhary, A. A.; Rao, B. S. M.; Lee, H. K.; J. Chromatogr., A 2009, 1216, 211.

31. Granby, K.; Andersen, J. H.; Christensen, H. B.; Anal. Chim. Acta 2004, 520, 165.

32. Tarbah, F. A.; Mahler, H.; Temme, O.; Daldrup, T.; Forensic Sci. Int. 2001, 121, 126.

33. Ameno, K.; Lee, S. K.; In, S. W.; Yang, J.Y.; Yoo, Y. C.; Ameno, S.; Kubota, T.; Kinoshita, H.; Forensic Sci. Int. 2001, 116, 59.

34. Liu, Q.; Zhou, L.; Zheng, N.; Zhuo, L.; Liu, L.; Forensic Sci. Int. 2009, 193, 88.

35. Parrón, T.; Hernández, A. F.; Villanueva, E.; Forensic Sci. Int. 1996, 79, 53.

36. Teixeira, H.; Proença, P.; Alvarenga, M.; Oliveira, M.; Marques, E. P.; Vieira, D. N.; Forensic Sci. Int. 2004, 143, 199.

37. Akcan, R.; Hilal, A.; Daglioglu, N.; Cekin, N.; Gulmen, M. K.; Forensic Sci. Int. 2009, 189, 82.

38. Wang, Y. Z.; Kruzik, P.; Helsberg, A.; Helsberg, I.; Rausch, W. D.; Forensic Sci. Int. 2007, 169, 157.

39. Giorgi, M.; Mengozzi, G.; Vet. Med. - Czech 2011, 56, 173.

40. Koc, F,; Yigit, Y.; Das, Y. K.; Gurel, Y.; Yarali, C.; J. Food Drug Anal. 2008, 16, 39.
41. Caldas, S. S.; Demoliner, A.; Primel, E. G.; J. Braz. Chem. Soc. 2009, 20, 125.

42. D’Archivio, A. A.; Mazzeo, M. F. P.; Ruggieri, F.; Talanta 2007, $71,25$.

43. Fernández, J. M.; Vázquez, P. P.; Vidal, J. L. M.; Anal. Chim. Acta 2000, 412, 131.

44. Menezes Filho, A.; dos Santos, F. N.; Pereira, P. A. P.; Microchem. J. 2010, 96, 39.

45. Gou, Y.; Eisert, R.; Pawliszyn, J.; J. Chromatogr., A 2000, 873, 137.

46. Wang, S.; Mu, H.; Bai, Y.; Zhang, Y.; Liu, H.; J. Chromatogr., B: Anal. Technol. Biomed. Life Sci. 2009, 877, 2961.

47. Totti, S.; Fernández, M.; Ghini, S.; Picó, Y.; Fini, F.; Mañes, J.; Girotti, S.; Talanta 2006, 69, 724.

48. Fernández M.; Picó, Y.; Mañes, J.; J. Chromatogr., A 2000, 871, 43.

49. Vichapong, J.; Burakham, R.; Srijaranai, S.; Grudpan, K.; Talanta 2011, 84, 1253.

50. Chen, H.; Chen, R.; Li, S.; J. Chromatogr., A 2010, 1217, 1244.

51. Fu, L.; Liu, X.; Hu, J.; Zhao, X.; Wang, H.; Wang, X.; Anal. Chim. Acta 2009, 632, 289.

52. Zhou, Q.; Pang, L.; Xião, J.; Microchim. Acta 2011, 172, 477.

53. Zhao, G.; Wang, C.; Wu, Q.; Wang, J; Anal. Methods 2011, 3, 1410 .

54. Nunes, G. S.; Santos, T. C. R.; Barceló, D.; Pimenta, A. S.; Ribeiro, M. L.; Quim. Nova 2002, 25, 214.

55. González-Rodríguez, R. M.; Rial-Otero, R.; Cancho-Grande, B.; Simal-Gándara, J.; J. Chromatogr., A 2008, 1196-1197, 100.

56. Zhang, J.; Lee, H. K.; J. Chromatogr., A 2006, 1117, 31.

57. Camargo, S.; David, M. D.; Woodward, L. A.; Qing Li, X.; Chemosphere 2004, 54, 1155.

58. Delgado, M. J. S.; Barroso, S. R.; Fernández-Tostado, G. T.; Polo-Díez, L. M.; J. Chromatogr., A 2001, 921, 287.

59. Lian, D. X.; Yang, L.; Yun, W. X.; Hua, S.; Hu, C.; J. Chromatogr., A 1991, 542, 526.

60. Albanis, T. A.; Hela, D. G.; J. Chromatogr., A 1995, 707, 283.

61. Lopes, R. P.; Augusti, D. V.; De Souza, L. F.; Santos, F. A.; Lima, J. A.; Vargas, E. A.; Augusti, R.; Anal. Methods 2011, 3, 606.

62. Damasceno, L. H. S.; Adorno, M. A. T.; Hirasawa, J. S.; Varesche, M. B. A.; Zaiat, M.; J. Braz. Chem. Soc. 2008, 19, 1158.

63. Liu, Z. M.; Zang, X. H.; Liu, W. H.; Wang, C.; Wang, Z.; Chin. Chem. Lett. 2009, 20, 213.

64. Goulart, S. M.; Alves, R. D.; Neves, A. A.; de Queiroz, J. H.; de Assis, T. C.; de Queiroz, M. E. L. R.; Anal. Chim. Acta 2010, $671,41$.

65. Osborn, R. K.; Edwards, S. G.; Wilcox, A.; Haydock, P. P. J.; Pest Manag. Sci. 2010, 66, 253.

66. Dixit, V.; Tewari, J. C.; Obendorf, S. K.; J. Chromatogr., A 2009, $1216,6394$. 
67. Pizzutti, I. R.; de KoK, A.; Hiemstra, M.; Wichert, C.; Prestes, O. D.; J. Chromatogr., A 2009, 1216, 4539.

68. Kmellár, B.; Fodor, P.; Pareja, L.; Ferrer, C.; Martínez-Uroz, M. A.; Valverde, A.; Fernadez-Alba, A. R.; J. Chromatogr., A 2008, 1215, 37.

69. Lesueur, C.; Knittl, P.; Gartner, M.; Mentler, A.; Fuerhacker, M.; Food Control 2008, 19, 906.

70. Ferrer, I.; Thurman, E. M.; J. Chromatogr., A 2007, 1175, 24.

71. Vieira, H. P.; Neves, A. A.; de Queiroz, M. E. L. R.; Quim. Nova 2007, 30, 535.

72. Rubensam, G.; Barreto, F.; Hoff, R. B.; Kist, T. L.; Pizzolato, T. M.; Anal. Chim. Acta 2011, 705, 24.

73. Goulart, S. M.; de Queiroz, M. E. L. R.; Neves, A. A.; de Queiroz, J. H.; Talanta 2008, 75, 1320.

74. De Pinho, G. P.; Neves, A. A.; de Queiroz, M. E. L. R.; Silvério, F. O.; Food Control 2010, 21, 1307.

75. De Pinho, G. P.; Neves, A. A.; de Queiroz, M. E. L. R.; Silvério, F. O.; Food Chem. 2010, 121, 251.

76. Chen, S.; Yu, X.; He, X.; Xie, D.; Fan, Y.; Peng, J.; Food Chem. 2009, 113, 1297.

77. Juhler, R. K.; J. Chromatogr., A 1997, 786, 145.

78. Lentza-Rizos, Ch.; Avramides, E. J.; Cherasco, F.; J. Chromatogr., A 2001, 912, 135.

79. Lentza-Rizos, Ch.; Avramides, E. J.; Visi, E.; J. Chromatogr., A 2001, 921, 297.

80. Marthe, D. B.; Bittencourt, L. M.; Queiroz, M. E. L. R.; Neves, A. A.; Quim. Nova 2010, 33, 1389.

81. Magalhães, E. J.; Nascentes, C. C.; Augusti, R.; Queiroz, M. E. L. R.; Silva, J. C. C.; Afonso, R. J. C. F; Am. J. Anal. Chem. 2012, 3, 118.

82. Agência Nacional de Vigilância Sanitária (ANVISA); Guia para Validação de Métodos Analíticos e Bioanalíticos-Resolução RE No. 899, Brazil, 2003, available at http://www. anvisa.gov.br/ legis/resol/2003/ re/899_03re.htm acessed in July 2011.
83. International Conference on Harmonisation (ICH); Validation of Analytical Procedures: Text and Methodology, Q2(R1), Geneva, 2005, available at http://www.ich.org/products/guidelines/ quality/article/quality-guidelines.html accessed in July 2011.

84. Instituto Nacional de Metrologia, Normalização e Qualidade Industrial (INMETRO); Orientações sobre Validação de Métodos Analíticos, DOQ-CGCRE-008, Brazil, 2010, available at http://www.inmetro.gov.br/Sidoq/Arquivos/CGCRE/DOQ/ DOQ-CGCRE-8_03.pdf accessed in July 2011.

85. Thomson M.; Ellison, S. L. R.; Wood, R.; Pure Appl. Chem. 2002, 74, 835 .

86. Meyer, P. C.; Zund, R. E. In Statistical Methods in Analytical Chemistry; John Wiley \& Sons: New York, 1993, p. 81.

87. Souza, S. V. C.; Junqueira, R. G.; Anal. Chim. Acta 2005, 552, 25.

88. Belsley, D. A.; Kuh, E.; Welsch, R. E. In Regression Diagnostics: Identifying Influential Data and Sources of Collinearity; Wiley: New York, 1980.

89. Horwitz, W.; Pure Appl. Chem. 1995, 67, 331.

90. Ryan, T. A.; Joiner, B. L. In Normal Probability Plots and Tests for Normality; The State College: Pennsylvania State University, 1976.

91. Levene, H. In Contributions to Probability and Statistics; Olkin, I.; Ghurye, S. G.; Hoeffding, W.; Madow, W. G.; Mann, H. B., eds.; Stanford University Press: Stanford, 1960.

92. Brown, M. B.; Forsythe, A. B.; J. Am. Stat. Assoc. 1974, 69, 364.

93. Durbin, J. Watson, G. S.; Biometrika 1951, 38, 159

94. Draper, N.; Smith, H. In Applied Regression Analysis; Wiley: New York, 1998.

95. Souza, S. V. C.; Lima, J. A.; Teodoro, J. C.; Junqueira, R. G.; Ciênc. Tecnol. Alim. 2007, 27, 823.

Submitted: January 2, 2012

Published online: June 5, 2012 